Check for updates

Cite this: Chem. Sci., 2018, 9, 990

\title{
Are multiple oxygen species selective in ethylene epoxidation on silver?†
}

\author{
Emilia A. Carbonio, (D)*ab Tulio C. R. Rocha, (D) Alexander Yu. Klyushin, (D) ab \\ Igor Píš, (D) de Elena Magnano, df Silvia Nappini, (D) d Simone Piccinin, (D) g Axel Knop- \\ Gericke, ${ }^{b}$ Robert Schlögl ${ }^{\text {bh }}$ and Travis E. Jones (D) *b
}

\begin{abstract}
The nature of the oxygen species active in ethylene epoxidation is a long-standing question. While the structure of the oxygen species that participates in total oxidation (nucleophilic oxygen) is known the atomic structure of the selective species (electrophilic oxygen) is still debated. Here, we use both in situ and UHV X-ray Photoelectron Spectroscopy (XPS) to study the interaction of oxygen with a silver surface. We show experimental evidence that the unreconstructed adsorbed atomic oxygen $\left(\mathrm{O}_{\text {ads }}\right)$ often argued to be active in epoxidation has a binding energy $(B E) \leq 528 \mathrm{eV}$, showing a core-level shift to lower BE with respect to the O-reconstructions, as previously predicted by DFT. Thus, contrary to the frequent assignment, adsorbed atomic oxygen cannot account for the electrophilic oxygen species with an $\mathrm{O}$ 1s $\mathrm{BE}$ of $530-531 \mathrm{eV}$, thought to be the active species in ethylene epoxidation. Moreover, we show that $\mathrm{O}_{\text {ads }}$ is present at very low O-coverages during in situ XPS measurements and that it can be obtained at slightly higher coverages in UHV at low temperature. DFT calculations support that only low coverages of $\mathrm{O}_{\text {ads }}$ are stable. The highly reactive species is titrated by background gases even at low temperature in UHV conditions. Our findings suggest that at least two different species could participate in the partial oxidation of ethylene on silver.
\end{abstract}

Received 1st November 2017 Accepted 26th November 2017

DOI: $10.1039 / \mathrm{c} 7 \mathrm{sc} 04728 \mathrm{~b}$

rsc.li/chemical-science has been shown to participate in the complete oxidation of ethylene. ${ }^{10}$ The latter, an electron deficient oxygen, has been proposed to open the $\mathrm{C}=\mathrm{C}$ double bond of ethylene, forming the COC ring through $\mathrm{O}$ insertion, ${ }^{\mathbf{9 , 1 1 , 1 2}}$ and has been shown to participate in epoxidation. ${ }^{13}$ Yet, while the atomic structure of nucleophilic oxygen is known, ${ }^{\mathbf{1 0 , 1 4 , 1 5}}$ the atomic structure of the active species for ethylene epoxidation is debated., ${ }^{\mathbf{4}, \mathbf{1 5}-17}$ This electrophilic species is thought to be weakly bound oxygen and, following early assignments, ${ }^{18,19}$ has been extensively interpreted as being unreconstructed adsorbed or dissolved atomic O. ${ }^{6,7,20-27}$ However, even in early publications such assignments appeared inconsistent. Campbell et al. ${ }^{28}$ using TPR (Temperature Programmed Reaction) and XPS, reported on an unreactive subsurface form of oxygen with BE of $\sim 528.5 \mathrm{eV}$ and proposed that it would be similar in nature to atomic O. Similarly, in two later publications Bukhtiyarov et al. ${ }^{\mathbf{2 9}, 30}$ observed that XPS spectra would only show a main component at $528.4 \mathrm{eV}$, although the presence of dissolved $O$ could be detected by TPD (Temperature Programmed Desorption). Consistent with the assignment of electrophilic oxygen to unreconstructed atomic oxygen, an oxometallacycle (OMC) mechanism has been developed wherein ethylene reacts with adsorbed $\mathrm{O}$ on the unreconstructed surface to make ethylene oxide and acetaldehyde. ${ }^{17,31-33}$

More recent publications from Rocca et al. ${ }^{34,35}$ report on $\mathrm{O}$ species with $\mathrm{BE}<528 \mathrm{eV}$ for a $\mathrm{Ag}(210)$ surface exposed to $\mathrm{O}_{2}$ at 
low temperatures. The authors attribute the low $\mathrm{BE} O$ 1s component to two $\mathrm{O}$ species: adsorbed $\mathrm{O}$ atoms in 4 -fold hollows and $\mathrm{O}-\mathrm{Ag}$ rows at the steps. Moreover, it was recently demonstrated by means of Density Functional Theory (DFT) calculations combined with experimentally measured $\mathrm{O}$ 1s BE and NEXAFS (Near Edge X-ray Absorption Fine Structure), that the spectroscopic features of unreconstructed atomic oxygen do not agree with those measured for the electrophilic species with a BE of $530-531 \mathrm{eV} \cdot{ }^{15}$ Furthermore, it was shown by DFT that when $\mathrm{Ag} / \mathrm{O}$ bonding is ionic, as is the case for atomic $\mathrm{O}$ on $\mathrm{Ag}$, more weakly bound atomic oxygen will have a lower $\mathrm{O} 1 \mathrm{~s} \mathrm{BE}$ and thus, it cannot account for the electrophilic species. ${ }^{16}$ Despite this, adsorbed atomic $\mathrm{O}$ is still assigned in the literature to unreconstructed atomic oxygen based on the $\mathrm{BE}$ of 530$531 \mathrm{eV}^{26}$

On $\mathrm{Ag}(111)$, Carlisle et al. ${ }^{36}$ reported that unreconstructed atomic oxygen could be present only at oxygen coverages below $0.05 \mathrm{ML}$, as seen by STM. In line with this observation, an investigation ${ }^{15}$ with fast in situ XPS measurements performed with a $\mathrm{Ag}(111)$ single crystal in $\mathrm{O}_{2}$ at $10^{-4}$ mbar showed that the $\mathrm{O} 1$ s spectra had a peak with $\mathrm{BE}<528 \mathrm{eV}$ that could only be seen for the first minutes of dosing, shifting with time to slightly higher BE. The low BE component was only observed for an Ocoverage of $\sim 0.05 \mathrm{ML}$. Although the shift in BE is small for this surface, it was interpreted as a transition from atomic oxygen on the unreconstructed silver surface to the formation of islands of O-reconstructions as coverage increased, since the reconstruction is thermodynamically favoured. ${ }^{15}$ In contrast, the computed BE difference of unreconstructed adsorbed atomic oxygen with respect to the O-reconstructions on the $\operatorname{Ag}(110)$ surface is larger. ${ }^{15}$ However, in the same study, for the $\mathrm{Ag}(110)$ surface no such low BE peak was observed when exposed to $10^{-4}$ mbar of $\mathrm{O}_{2}$. The sticking coefficient for the dissociative adsorption of $\mathrm{O}_{2}$ on $\mathrm{Ag}(110)$ has been reported to be two to three orders of magnitude higher than on $\mathrm{Ag}(111) \cdot{ }^{28,37-42}$ Thus, it can be expected that the O-coverage would increase faster on $\mathrm{Ag}(110)$ than on $\mathrm{Ag}(111)$, implying a reconstructed surface would form faster on $\mathrm{Ag}(110)$ under $\mathrm{O}_{2}$.

It is well known that when a $\mathrm{Ag}(110)$ surface is exposed to $\mathrm{O}_{2}$ at conditions such that dissociative adsorption occurs, a series of $p(N \times 1)$ added row reconstructions can easily be produced. $^{28,42}$ Moreover, due to the relatively high sticking coefficient of oxygen on the $\mathrm{Ag}(110)$ surface, these reconstructions can be made under low $\mathrm{O}_{2}$ dosing in UHV compatible system. ${ }^{28,42}$ Such conditions are necessary when studying highly reactive species, which can be undetectable if clean-off reactions with background gases, for instance CO, become relevant. These types of unwanted reactions are typical for adsorbed atomic O, as shown by low temperature STM measurements. ${ }^{43}$

Herein, we perform in situ experiments on a $\mathrm{Ag}(110)$ surface by exposing the single crystal to $\mathrm{O}_{2}$ at $10^{-5} \mathrm{mbar}$ and $10^{-6} \mathrm{mbar}$ at $423 \mathrm{~K}$ and taking fast $\mathrm{O} 1 \mathrm{~s}$ spectra (30 s per spectra). We show that a low BE species is only present at low coverages $\left(\theta_{\mathrm{O}}<\right.$ $0.04 \mathrm{ML}$ ) which for $\mathrm{Ag}(110)$, can only be obtained at low $\mathrm{O}_{2}$ pressure $\left(10^{-6} \mathrm{mbar}\right)$. We assign this species with $\mathrm{BE} \leq 528 \mathrm{eV}$ to unreconstructed atomic $\mathrm{O}$, as predicted by DFT and in line with previous interpretations. ${ }^{15}$ We confirm the assignment to unreconstructed atomic oxygen by XPS measurements of $\mathrm{O} /$ $\mathrm{Ag}(110)$ at $120 \mathrm{~K}$ in UHV where the O-reconstruction, although thermodynamically favoured, ${ }^{15}$ is kinetically hindered, and higher coverages $(\sim 0.1 \mathrm{ML})$ of atomic adsorbed $\mathrm{O}$ on the unreconstructed silver can be obtained.

\section{Methodology}

\section{Experimental details}

The in situ XPS measurements were performed at the ISISS beamline in the BESSY II synchrotron radiation facility of the Helmholtz-Zentrum Berlin. Details about the system can be found elsewhere. ${ }^{\mathbf{4 4 , 4 5}}$ The $\mathrm{Ag}(110)$ single crystal was polished and oriented to an accuracy $<1^{\circ}$. The crystal was cleaned by repeating cycles of $\mathrm{O}_{2}$ treatment at $10^{-3}$ mbar at $423 \mathrm{~K}$ for $20 \mathrm{~min}$, followed by Ar sputtering at $1.5 \mathrm{kV}$ for $20 \mathrm{~min}$ and annealing at $673 \mathrm{~K}$ in vacuum $\left(5 \times 10^{-8} \mathrm{mbar}\right)$ for $5 \mathrm{~min}$. Large amounts of $\mathrm{C}, \mathrm{Cl}, \mathrm{S}$ and $\mathrm{Si}$ segregated to the surface after the initial $\mathrm{O}_{2}$ exposure, but after several cleaning cycles, only $\mathrm{Ag}$ and $\mathrm{O}$ were observed for exposures shorter than 1-2 h. The crystal was placed in a sapphire sample holder and held by a tungsten wire. Heating was done from the backside with an IR laser on a stainless-steel plate in contact with the crystal. The sample temperature was measured with a K-type thermocouple and controlled by adjusting the laser power using a PID feedback loop. Photon energies were chosen so that photoelectrons with the same kinetic energy of $150 \mathrm{eV}$ could be measured for the different elements, giving an equivalent to an inelastic mean free path of $0.5 \mathrm{~nm}$.

The low temperature measurements were performed in UHV at the $\mathrm{BACH}$ beamline in Elettra Sincrotrone Trieste. ${ }^{46,47}$ For these measurements the $\mathrm{Ag}(110)$ single crystal was cleaned by cycles of Ar sputtering at $1.5 \mathrm{kV}$ for $20 \mathrm{~min}$, annealing in $\mathrm{O}_{2}$ at $10^{-6}$ mbar at $453 \mathrm{~K}$ and subsequent annealing in UHV at $673 \mathrm{~K}$. The cycles were repeated until no $\mathrm{C}$ was observed on the surface. A photon energy of $670 \mathrm{eV}$ was used for acquisition of all the core-lines. For the low temperature measurements, the sample was cooled by flowing liquid $\mathrm{N}_{2}$ through the manipulator. Sample heating was done by a tungsten filament placed behind the sample holder. The sample temperature was measured with a N-type thermocouple. Oxygen dosing was done by backfilling the UHV chamber with $\mathrm{O}_{2}$ at pressures in the range $10^{-7}$ to $10^{-6}$ mbar.

In all cases, the binding energy scale for each spectra was calibrated by the Fermi edge measured with the same photon energy.

More details about the fitting procedure and other information are given in the ESI. $\dagger$

\section{Computational details}

Calculations were performed with the Quantum ESPRESSO package $^{48}$ using the Perdew, Burke, and Ernzerhof (PBE) exchange and correlation potential ${ }^{49}$ and the exchange-hole dipole moment $(\mathrm{XDM})^{50,51}$ dispersion correction. Projector augmented wave (PAW) potentials were taken from the PS library, ${ }^{52}$ and we employed a kinetic energy (charge density) cutoff of 70 Ry (700 Ry). Surfaces were modeled as five-layer 
slabs separated by $15 \AA$ of vacuum with the bottom two layers were held fixed at their computed bulk values. A $k$-point mesh equivalent to at least $(12 \times 12)$ for the $(1 \times 1)$ surface-unit-cell was used with Marzari-Vanderbilt cold smearing ${ }^{53}$ and a smearing parameter of 0.01 Ry. Core level shifts were computed with the $\Delta$ SCF (Self Consistent Field) method to capture both initial and final state effects. ${ }^{54}$ Climbing image nudged elastic band (NEB) calculations were performed using 8-10 images with a single climbing image, a $k$-point mesh equivalent to $(8 \times 8)$ for the $(1 \times 1)$ surface-unit-cell, and a kinetic energy (charge density) cutoff of $30 \mathrm{Ry}$ (300 Ry), unless otherwise noted. This reduced convergence criteria results in adsorption energy changes of only $0.1 \mathrm{eV}$.

\section{Results and discussion}

\section{In Situ measurements}

We begin our investigation studying the interaction of $\mathrm{O}_{2}$ with a $\mathrm{Ag}(110)$ surface by performing fast in situ XPS measurements at low pressures, in order to characterize the species present at low coverages. When exposed to $10^{-5} \mathrm{mbar} \mathrm{O}_{2}$ at $423 \mathrm{~K}$, the $\mathrm{O} 1 \mathrm{~s}$ spectra shows only a main peak at $528.2 \mathrm{eV}$ and does not change significantly with time (see Fig. 1a). This BE indicates that an Oreconstruction is formed ${ }^{15,28}$ immediately after exposure. The situation changes when the experiment is done at $10^{-6} \mathrm{mbar}$, which is close to the predicted minimum pressure needed to stabilize the $p(N \times 1)$ reconstructions at $423 \mathrm{~K} .{ }^{15}$ Thus, we might expect unreconstructed atomic oxygen to be stable, at least transiently. We find that at $10^{-6} \mathrm{mbar}_{2}$ at $423 \mathrm{~K}$, an oxygen species with a $\mathrm{BE}$ of $527.9 \mathrm{eV}$ is present after 30 seconds of dosing (Fig. 1b), with an estimated coverage of $\sim 0.02$ ML. This $\mathrm{BE}$ is in line with that expected for unreconstructed atomic $\mathrm{O}$ from DFT calculations. ${ }^{15,16}$ The $\mathrm{O} 1 \mathrm{~s}$ BE shifts rapidly to higher BEs within the first three minutes (see Fig. 2a) reaching a BE of

a)

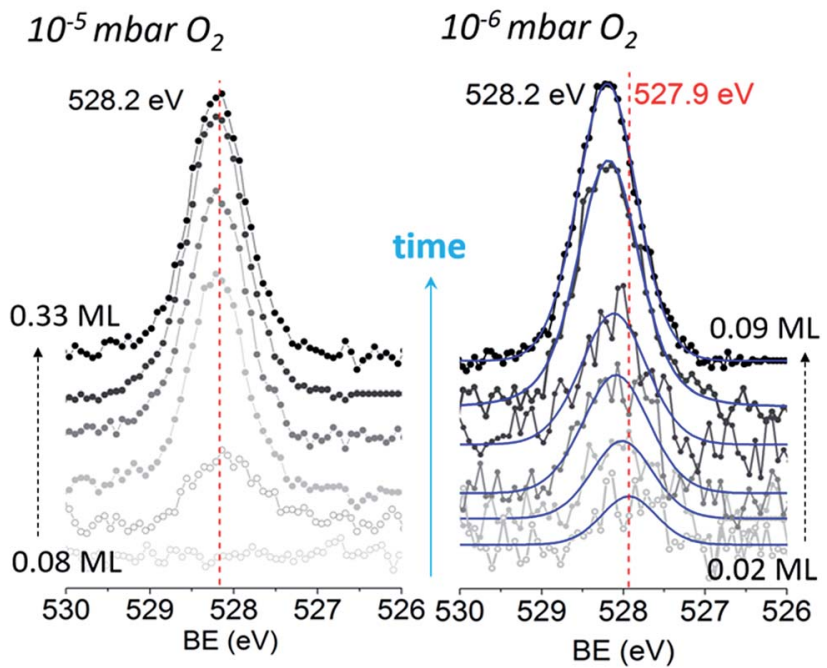

Fig. $1 \mathrm{O}$ 1s time evolution on $\mathrm{Ag}(110)$ during exposure to $\mathrm{O}_{2}$ at $10^{-5}$ mbar and $10^{-6}$ mbar at $423 \mathrm{~K}$. $\sim 528.15 \mathrm{eV}$ and a coverage of $\sim 0.04 \mathrm{ML}$, indicating a surface reconstruction has precipitated at this coverage. After this point, coverage increases at a slower rate from $\sim 0.04 \mathrm{ML}$ to $\sim 0.09 \mathrm{ML}$ in 8 minutes and the $\mathrm{BE}$ of the $\mathrm{O} 1 \mathrm{~s}$ spectra is approximately constant, reaching a value of $528.2 \mathrm{eV}$, which corresponds to that of the $p(N \times 1)$ reconstructions. ${ }^{15,28}$ This behavior is similar to what was previously observed on $\mathrm{Ag}(111)$ at $10^{-4}$ mbar $^{15}$ and is attributed to the transition from $\mathrm{O}$ adsorbed on the unreconstructed silver to the formation of reconstructed $p(N \times 1)$ islands. These findings are supported by $a b$ initio atomistic thermodynamics. ${ }^{15,55}$

Previous work has shown that the adsorption energy of oxygen is higher in a $p(N \times 1)$ reconstruction than on the unreconstructed surface. ${ }^{15}$ Inspection of Tables $1 \mathrm{~S}$ and $2 \mathrm{~S}$ in $\mathrm{ESI} \dagger$ confirm this finding even for a low coverage of oxygen on the unreconstructed surface. Thus-ignoring changes in the vibrational free energy, which are expected to be small ${ }^{55}$ unreconstructed atomic oxygen will only be favored over the oxygen induced $p(N \times 1)$ reconstructions when the configurational entropy difference between the two phases is high. The difference in surface free energy for equal coverages of reconstructed and unreconstructed can then be given by:

$$
\Delta \gamma(T)=\Delta E_{\mathrm{ads}}-T \Delta S_{\mathrm{conf}}
$$

where $\Delta E_{\text {ads }}$ is the difference in adsorption energy between oxygen on the unreconstructed $\mathrm{Ag}(110)$ and a $p(\mathrm{~N} \times 1)$ reconstruction:

$$
\Delta E_{\mathrm{ads}}=\left(E_{\mathrm{ads}, \mathrm{O}}-E_{p(N \times 1)}\right)
$$

The difference in configurational entropy in eqn (1) is:

$$
\Delta S_{\text {conf }}=S_{\text {conf }, \mathrm{O}}-S_{\text {conf }, p(N \times 1)}
$$

where the configurational entropy for an adatom at coverage $\theta$ on the unreconstructed surface is given by:

$$
S_{\mathrm{conf}, \mathrm{O}}=-\frac{k_{\mathrm{B}}}{\theta}[(1-\theta) \ln (1-\theta)+\theta \ln (\theta)]
$$

For simplicity, the configurational entropy of an $\mathrm{O}$ atom in the surface reconstruction is taken to be zero.
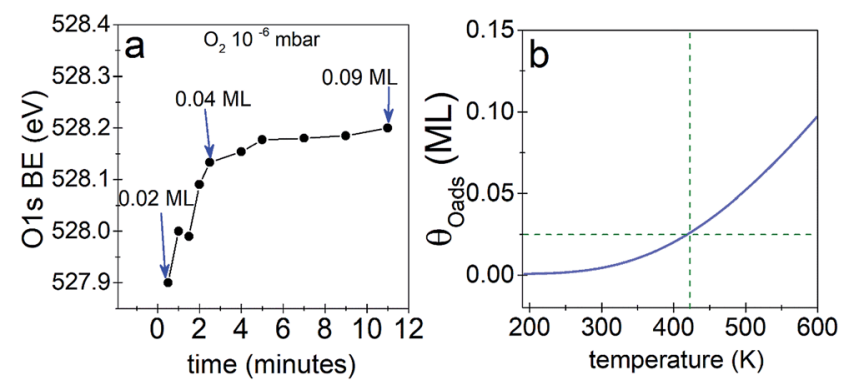

Fig. 2 (a) $\mathrm{O} 1 \mathrm{~s} \mathrm{BE}$ as a function of time for $\mathrm{Ag}(110)$ in $10^{-6} \mathrm{mbar}_{2}$ at $423 \mathrm{~K}$, (b) predicted maximum coverage of unreconstructed atomic oxygen as a function of temperature, assuming the added-row $\mathrm{Ag}-\mathrm{O}$ chains in the $p(N \times 1)$ contribute no configurational entropy. The dashed line shows the predicted coverage at the temperature of the experiment. 
Because we are concerned with low-coverage phases, we take the adsorption energies of oxygen in their low-coverage limits, the $p(4 \times 1)$ reconstruction and 1/16 ML oxygen in the fourfold hollow sites of the $\mathrm{Ag}(110)$ surface (see ESI for more details, Table $3 \mathrm{~S}$ and Fig. 1S $\dagger$ ). With these adsorption energies, the maximum coverage of adsorbed oxygen on the unreconstructed surface can be found by setting $\Delta \gamma(T)=0$.

The predicted maximum coverage of oxygen on the unreconstructed surface is shown in Fig. $2 \mathrm{~b}$. This approach predicts a maximum coverage of atomic oxygen on unreconstructed $\mathrm{Ag}(110)$ of $\sim 0.02$ to $0.03 \mathrm{ML}$ at $423 \mathrm{~K}$, in good agreement with the experimental results.

With the preceding analysis in mind it is worth returning to the experiments performed at $10^{-5}$ mbar on the $\mathrm{Ag}(110)$. The absence of the low BE feature in these experiments can now be understood as due to the faster increase in coverage at this pressure (see Fig. $3 \mathrm{~S}^{\dagger}$ ). The first measured spectra after exposure of $\mathrm{O}_{2}$ at $10^{-5}$ mbar corresponds to an estimated coverage of $\sim 0.08 \mathrm{ML}$, a coverage at which both our experimental and theoretical (see Fig. 2) results show unreconstructed atomic $\mathrm{O}$ is no longer stable.

By this, it may be argued that for the pressure used in ref. 15 $\left(10^{-4} \mathrm{mbar}_{2}\right)$ the absence of a low BE on the $\mathrm{Ag}(110)$ surface is probably due to a O-coverage higher than $0.04 \mathrm{ML}$ already at very short times.

It is well known that on clean silver surfaces steps act as a source of mobile $\mathrm{Ag}$ atoms even at room temperature $\mathrm{e}^{56,57}$ and the detachment of these $\mathrm{Ag}$ atoms is a thermally activated process. ${ }^{56}$ Ostwald ripening of two dimensional islands on $\operatorname{Ag}(110)$ has been observed at temperatures above $160 \mathrm{K.}{ }^{56,58}$ The growth rate of O-reconstructions on $\mathrm{Ag}(110)$ at $190 \mathrm{~K}$ was found to be lower than the supply rate of oxygen atoms, remaining constant while the O-coverage increased. ${ }^{56}$ The equilibrium Ag adatom density might not be sustained at low temperatures if the $\mathrm{Ag}$ atom detachment from the steps is kinetically limited, even if thermodynamically favoured. Consequently, at lower temperatures unreconstructed atomic $\mathrm{O}$ can be expected to be present at the silver surface. Thus, we turn to low temperature experiments with the aim of obtaining unreconstructed atomic $\mathrm{O}$, since this should be a stable species for longer time at low temperature and in UHV conditions.

\section{Low temperature measurements}

We continue by analysing the interaction of $\mathrm{O}_{2}$ with a $\mathrm{Ag}(110)$ surface by dosing $\mathrm{O}_{2}$ at $453 \mathrm{~K}$ and then at $120 \mathrm{~K}$. Although at 120 $\mathrm{K}$ the main adsorption form of oxygen is molecular, dissociation is expected due to low activation energy, which we computed to be only $0.4 \mathrm{eV}$ for $\mathrm{O}_{2}$ dissociation along the [001] or [1-10] direction at $1 / 16 \mathrm{ML} \mathrm{O}$ coverage $\left(\mathrm{O}_{2}\right.$ adsorption geometries given in Fig. $2 \mathrm{~S} \dagger$ ). In fact, dissociation has been observed to occur to some extent already at this temperature by STM, ${ }^{36,59}$ though the formation of the added row reconstructions was found to start at $170-200 \mathrm{~K} .^{\mathbf{4 3 , 5 9 , 6 0}}$

Taking into consideration the results obtained for the in situ measurements, and that the sticking coefficient for $\mathrm{O}_{2}$ is higher at lower temperatures, ${ }^{\mathbf{3 8 - 4 0 , 4 2}}$ the $\mathrm{O}_{2}$ exposure was done using pressures in the range $10^{-7}$ to $10^{-6} \mathrm{mbar}$, in order to obtain low O-coverages. Moreover, low $\mathrm{O}_{2}$ exposures are preferred to minimize the formation of $\mathrm{OH}$ and $\mathrm{CO}_{3}$ (ref. 28 and 61) that might occur due to the fast reaction of unreconstructed atomic $\mathrm{O}$ with background gases $\mathrm{CO}$ and $\mathrm{H}_{2} \mathrm{O} .{ }^{43}$

Fig. 3 shows the $\mathrm{O} 1 \mathrm{~s}$ and $\mathrm{Ag} 3 \mathrm{~d}$ spectra of a $\mathrm{Ag}(110)$ surface exposed to different amounts of $\mathrm{O}_{2}$ at different temperatures (indicated in the figure). The spectra acquired for the clean surface is also shown for comparison. The resulting binding energies are summarized in Table $4 \mathrm{~S}$. $\dagger$ The clean surface shows a single component with a $\mathrm{BE}$ of $368.25 \mathrm{eV}$ for the $\mathrm{Ag} 3 \mathrm{~d}_{5 / 2}$ coreline. When $600 \mathrm{~L} \mathrm{O}_{2}$ is dosed at $453 \mathrm{~K}$, the $\mathrm{O} 1 \mathrm{~s}$ spectra shows a main peak at $528.3 \mathrm{eV}$. This $\mathrm{BE}$ is in agreement with the measured $^{15,28}$ and calculated ${ }^{15} \mathrm{BE}$ for the added row reconstructions on $\mathrm{Ag}(110)$ and in line with the measured BE from our in situ experiments (528.2 eV, see Fig. 1). Other small contributions are observed at $529.2 \mathrm{eV}$ and $530 \mathrm{eV}$. The BEs of these species have previously been assigned to oxide-like layers and electrophilic oxygen, respectively. ${ }^{6,15}$ The corresponding Ag $3 \mathrm{~d}$ spectra shows a main component with a BE of $368.25 \mathrm{eV}$ and a smaller component at a $\mathrm{BE}$ of $367.85 \mathrm{eV}$, which is due to the $\mathrm{Ag}^{\delta+}$ formation due to the presence of oxygen atoms on the surface. ${ }^{6,23}$ Although most metals show a core-level shift (CLS) to higher BE for higher oxidation states, it is well known that for silver there is a CLS to lower BE. ${ }^{62}$ The $\mathrm{O} 1 \mathrm{~s}$ spectra for the $\mathrm{Ag}(110)$ exposed to $60 \mathrm{~L}$ and $120 \mathrm{~L}$ at $120 \mathrm{~K}$ shows two components. One at $529.7 \mathrm{eV}$ was assigned to molecularly adsorbed oxygen based on our DFT calculations showing $\mathrm{O}_{2}$ adsorbed in

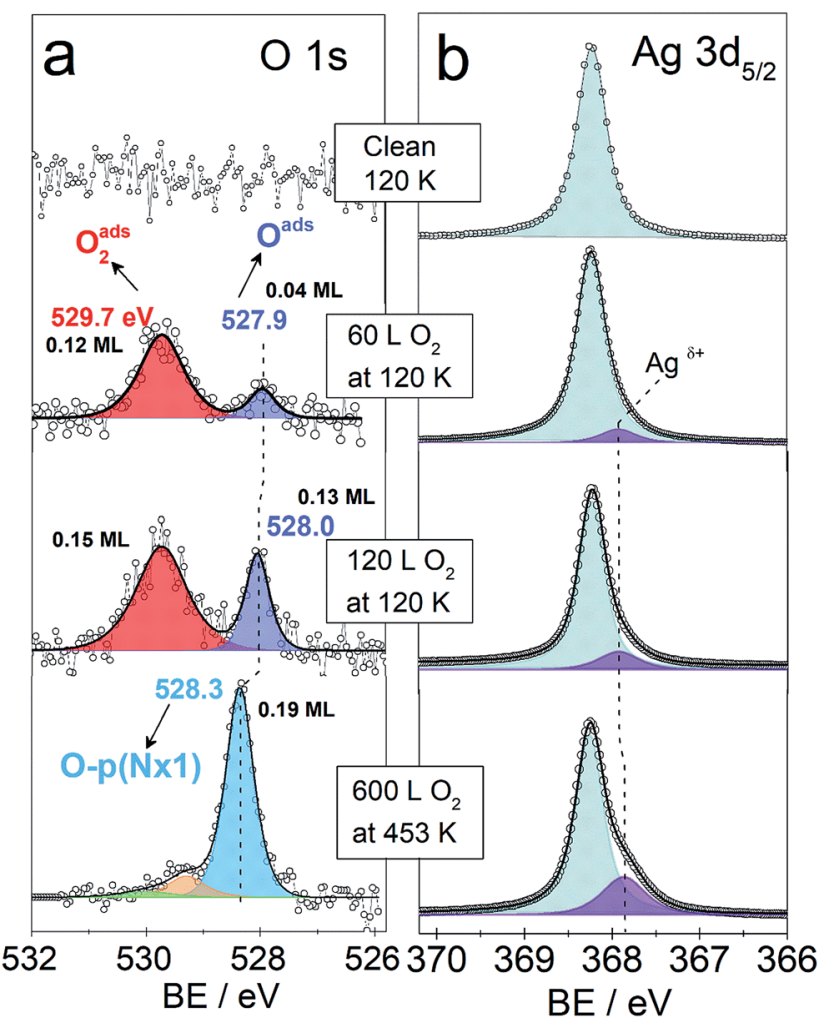

Fig. $3 \mathrm{O} 1 \mathrm{~s}$ and $\mathrm{Ag} 3 \mathrm{~d}_{5 / 2}$ spectra of clean and oxygen covered $\mathrm{Ag}$ (110) surface. Temperature and oxygen dosing are indicated in the figure. 
a fourfold hollow (FFH) site with the interatomic axis parallel to the [001] or [1-10] direction (adsorption geometries in Fig. 2S $\dagger$ ) has a computed $\mathrm{O} 1 \mathrm{~s} \mathrm{BE}$ of $529.7 \mathrm{eV}$, consistent with literature values. ${ }^{28}$ A second oxygen species at $527.9-528 \mathrm{eV}$ is consistent with the computed $\mathrm{O}$ 1s binding energy of unreconstructed atomic oxygen ${ }^{\mathbf{1 5}}$ and the in situ measurements of this species (see Fig. 1). Additionally, the corresponding Ag 3d spectra also show a small component at lower BE, $367.9 \mathrm{eV}$, due to $\mathrm{Ag}^{\delta+}$ sites.

We observe that the amount of the low BE species in the $\mathrm{O} 1 \mathrm{~s}$ core-level spectra decreases with time. For instance, after 35 minutes at $120 \mathrm{~K}$ with a maximum base pressure of $10^{-9}$ mbar, the amount decreases by at least half (see Fig. $4 \mathrm{~S} \dagger$ ). This is consistent with the previously reported high reactivity of unreconstructed atomic oxygen. ${ }^{59,60}$ Two kinetically different atomic $\mathrm{O}$ species have been previously described for $\mathrm{CO}$ oxidation to $\mathrm{CO}_{2} \cdot{ }^{40,63,64}$ For O pre-covered $\mathrm{Ag}(110)$ exposed to $\mathrm{CO}$, the formation of $\mathrm{CO}_{2}$ was observed to be slow at high oxygen coverages and to accelerate at lower coverages, ${ }^{\mathbf{4 0}}$ due to the more reactive unreconstructed adsorbed $\mathrm{O}$ atoms present at the low coverage limit. Furthermore, unreconstructed adsorbed $\mathrm{O}$ has been reported to react with $\mathrm{CO}$ at temperatures as low as $70 \mathrm{~K}^{43}$ It was observed by low temperature STM measurements, that the amount of adsorbed $\mathrm{O}$ atoms on the unreconstructed silver would decrease due to clean-off reactions with the background gas of the UHV chamber even at a base pressures lower than $1 \times 10^{-10}$ mbar at $110 \mathrm{~K} .^{43}$

As mentioned before, DFT calculations predict unreconstructed atomic oxygen on silver to have a $\mathrm{BE} \leq 528 \mathrm{eV}$ (ref. 15 and 16) in contrast to the $p(N \times 1)$ reconstructions on $\operatorname{Ag}(110)$ for which it predicts a $\mathrm{BE}$ of $528.5 \mathrm{eV} .^{15}$ This gives a CLS of $\sim 0.5 \mathrm{eV}$ to lower $\mathrm{BE}$ for $\mathrm{O}$ on the unreconstructed $\mathrm{Ag}(110)$ surface. Thus, the BE predicted by DFT, the measured BE of 527.9-528 eV and the high reactivity observed for this species, are all characteristics consistent with atomic $\mathrm{O}$ adsorbed on unreconstructed $\mathrm{Ag}(110)$. This is consistent with the low $\mathrm{BE}$ component seen in the in situ experiments (see Fig. 1). The higher coverage attainable at low temperatures is attributed to the reconstructions' formation being kinetically hindered at $120 \mathrm{~K},{ }^{59,60}$ due to the lower mobility of $\mathrm{Ag}$ atoms at low temperature. $^{56}$

\section{Adsorbed atomic $O$ in ethylene epoxidation}

The generally accepted idea that reconstructed atomic oxygen, assigned to nucleophilic oxygen, participates in the complete oxidation of ethylene to $\mathrm{CO}_{2}$ and that unreconstructed adsorbed atomic oxygen, often assigned to electrophilic oxygen, can participate in ethylene oxide (EO) production, motivated a series of theoretical investigations on the reaction mechanism for ethylene epoxidation. ${ }^{17,31-33}$ On unpromoted silver, experimental evidence ${ }^{\mathbf{1 0 , 1 4 , 2 7}}$ shows that the reaction of ethylene with O-reconstructions favors total combustion giving $\mathrm{CO}_{2}$ as a product, which is supported by theory. ${ }^{10,32}$ For the reconstructions, DFT calculations show that the reaction of ethylene and atomic $\mathrm{O}$ has a low barrier towards acetaldehyde $(\mathrm{AcH})$ formation, ${ }^{10}$ which rapidly burns. ${ }^{\mathbf{1 0 , 1 4 , 3 1}}$ Conversely, for unreconstructed adsorbed atomic oxygen on silver, DFT calculations have been reported to give similar barriers for the conversion of ethylene to $\mathrm{EO}$ and $\mathrm{AcH},{ }^{31,33,65}$ predicting a $~ 50 \%$ EO selectivity for unpromoted silver catalysts. ${ }^{31}$ This agrees with many experimentally observed selectivities, ${ }^{\mathbf{1 , 2 , 6 6}}$ that were believed to take place on unpromoted silver catalysts thus, unreconstructed atomic $O$ was thought to be the active species in ethylene epoxidation and was assigned to electrophilic oxygen. ${ }^{19}$

However, we demonstrate that unreconstructed atomic oxygen is present at very low O-coverages and can be only detected transiently during in situ measurements. At the temperature and pressure relevant for ethylene epoxidation only 2 oxygen species have been predicted to be stable by $a b$ initio atomistic thermodynamic studies: the surface reconstruction (nucleophilic oxygen) and unreconstructed atomic O. ${ }^{55,67}$ The O-reconstruction is always thermodynamically favored under ethylene epoxidation conditions ${ }^{\mathbf{1 5}}$ making unlikely that unreconstructed $\mathrm{O}$ would be present at the surface under equilibrium conditions. However, low coverages of such species might be present ${ }^{55,67}$ if the formation of the reconstruction was limited by kinetics, as suggested by microkinetic modeling: ${ }^{68}$

Now consider that on silver under $\mathrm{O}_{2}$ at $423-520 \mathrm{~K}$ nucleophilic oxygen is the first $\mathrm{O}$ species detected while electrophilic oxygen is obtained only after longer times of exposures., ${ }^{\mathbf{6}, 18}$ Moreover, electrophilic oxygen is more rapidly obtained by increasing the $\mathrm{O}_{2}$ pressure and substrate temperature ${ }^{6,29}$ or by exposing the silver catalyst to the reaction mixture $\left(\mathrm{C}_{2} \mathrm{H}_{4}+\right.$ $\left.\mathrm{O}_{2}\right) \cdot{ }^{13,27}$ Thus, adsorbed atomic oxygen on the unreconstructed silver surface which is (as shown herein) a highly reactive species detected only at low coverages its unlikely to survive under such conditions used to obtain high concentration of electrophilic oxygen for UHV studies. ${ }^{1327,29}$ Furthermore, the maximum obtainable coverage of unreconstructed atomic $\mathrm{O}$ of ca. 0.02 ML (see Fig. 1 and 2) is much lower than to the $\mathrm{O}$ reconstruction coverage of $0.5-0.7 \mathrm{ML}$ observed in $\mathrm{UHV}^{\mathbf{1 4 , 2 8 , 3 9}}$ and under reaction conditions. ${ }^{6,15}$ These combined characteristics of high reactivity and very low coverage have prevented the species from being accurately characterized in the past by spectroscopic techniques both in UHV and during in situ measurements. Considering that there is small spectroscopic difference between these species it is reasonable to think that a very low coverage of unreconstructed $\mathrm{O}$ atoms would remain "undetected" even by in situ techniques. Thus, although predicted to exist, unreconstructed atomic $\mathrm{O}$ has been erroneously assigned to the so called electrophilic oxygen with a BE of 530$531 \mathrm{eV}$ observed on silver catalysts in $\mathrm{UHV}^{13,27,29}$ and under reaction conditions $s^{5,7,20,21}$ and shown to participate in epoxidation. $^{\mathbf{1 3}}$

The question then remains if the oxygen species identified in this work is possibly also active in epoxidation. To answer this we turned to testing the mechanism of the reaction of oxygen on the unreconstructed $\operatorname{Ag}(110)$ with ethylene. Following the convergence tests (see Table $5 \mathrm{~S} \dagger)$, we employed a $(4 \times 4)$ cell with a $(3 \times 3) k$-point mesh, a kinetic energy (charge density) cutoff of 40 Ry (400 Ry), and XDM dispersion corrections. The results are summarized in Fig. 4 (see also Table $6 \mathrm{~S} \dagger$ ). Inspection of Fig. 4 reveals ethylene can react with a low 


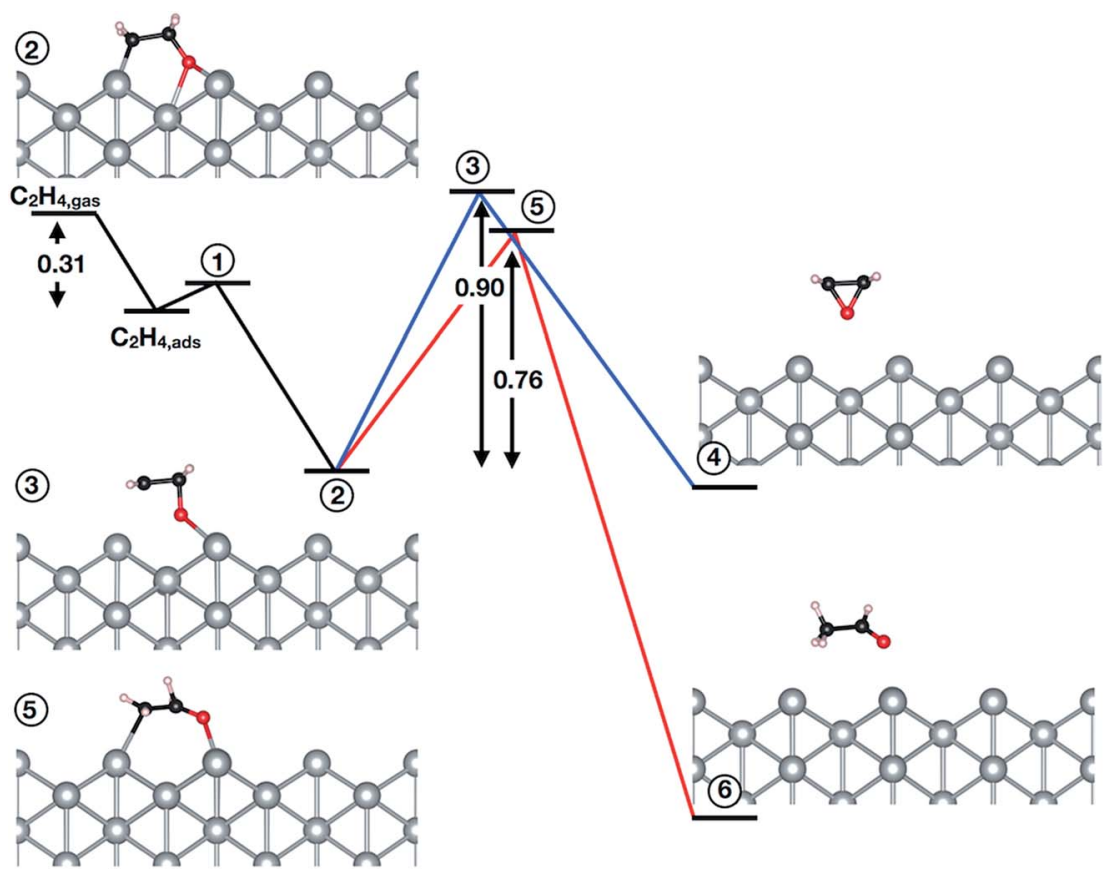

Fig. 4 Reaction of ethylene with $\mathrm{O}_{\text {ads }}$ on $\mathrm{Ag}(110)$ in a $(4 \times 4)$ cell. The black lines indicate the formation of the OMC (step 2). The blue $(\mathrm{red})$ lines show the activation energy associated with $\mathrm{EO}(\mathrm{AcH})$ formation through the transition state labeled state 3 (5).

coverage $(\theta=1 / 16 \mathrm{ML})$ of oxygen adsorbed on the unreconstructed $\mathrm{Ag}(110)$ through an oxometallacycle (OMC) mechanism, as has been observed for other surfaces ${ }^{31,66,69,70}$ and a high coverage $(\theta=1 / 4 \mathrm{ML})$ of oxygen on the unreconstructed $\mathrm{Ag}(110) .{ }^{31}$ The first step in the reaction is ethylene adsorption, which is $0.31 \mathrm{eV}$ exothermic when dispersion corrections are included. Following adsorption, the (partial) oxidation of ethylene proceeds by $\mathrm{OMC}$ formation, as the $\mathrm{C}-\mathrm{H}$ bond is too strong to make hydrogen abstraction from ethylene feasible. ${ }^{31}$ We find that OMC formation is weakly activated, with $E_{\mathrm{a}}=$ $0.09 \mathrm{eV}$.

Both EO and AcH can be formed through decomposition of the surface OMC. Assuming the EO produced in this reaction does not further decompose-isotope labeling studies on silver sponge suggest $10 \%$ of the $\mathrm{EO}$ is burned ${ }^{71}$-and noting that $\mathrm{AcH}$ rapidly combusts ${ }^{72,73}$ allows the branching ratio associated with $\mathrm{EO}$ and $\mathrm{AcH}$ formation to be viewed as a computational measure of the maximum selectivity afforded by an OMC mechanism..$^{10,31,66,69,74-76}$ From this measure one would predict the low-coverage phase of $\mathrm{O}_{\text {ads }}$ investigated in this work is not selective to $\mathrm{EO}$, with the barrier to AcH formation $(0.76 \mathrm{eV})$ $0.14 \mathrm{eV}$ lower than the barrier to EO formation $(0.90 \mathrm{eV})$.

It is interesting to note, however, that at a higher coverage the OMC is thought to decompose more selectively towards EO. ${ }^{31,77}$ To test this we recomputed the branching ratio using a (2 $\times 2$ ) cell and found no evidence increasing the OMC coverage will change the preference to $\mathrm{AcH}$ (see Table $7 \mathrm{~S}$ and $8 \mathrm{~S} \dagger$ ). We further verified the absence of dispersion corrections and a different pseudopotential library do not appreciably alter the computed branching ratio (see Table $7 \mathrm{~S}^{\dagger}$ ).

Our results then suggest the oxygen adsorbed on unreconstructed $\mathrm{Ag}(110)$ identified in this work will not be selective towards EO. However, the small difference in $\mathrm{AcH} / \mathrm{EO}$ activation energy implies $\mathrm{O}_{\mathrm{ads}}$ may produce $\mathrm{EO}$ as a minority product with $\mathrm{AcH}$, though perhaps less so than oxygen on unreconstructed $\operatorname{Ag}(111)$ or $\operatorname{Ag}(100){ }^{31,66,69}$ This behavior is in contrast to reconstructed atomic oxygen on the $\mathrm{Ag}(110)$ which - with an $E_{\mathrm{a}}$ to $\mathrm{AcH}$ more than $0.4 \mathrm{eV}$ lower than that to $\mathrm{EO}^{10}$ - is selective towards $\mathrm{AcH}$, and hence, $\mathrm{CO}_{2}$. Furthermore, in the presence of promoters the $\mathrm{AcH} / \mathrm{EO}$ branching ratio associated with the reaction of $\mathrm{O}_{\mathrm{ads}}$ on $\mathrm{Ag}(110)$ may shift towards EO. Such behavior has already been found in calculations of the OMC mechanism in the presence of halogens ${ }^{74}$ and $\mathrm{Cs}^{76,78}$ on $\mathrm{Ag}(111)$.

The combination of the experimental evidence show that unreconstructed $\mathrm{O}$ and electrophilic oxygen are different species and DFT indicates that $\mathrm{O}$ on the unreconstructed surface may participate in the partial oxidation of ethylene. Thus, two species may be active in epoxidation. First, the covalently bond type of oxygen ${ }^{16}$ (of debated structure) with a BE of $530-531 \mathrm{eV}$ (electrophilic oxygen)..$^{5,6,13,29,79}$ Second, the $O$ adsorbed on the unreconstructed surface with a $\mathrm{BE} \leq 528 \mathrm{eV}$ as shown herein. The ultimate test for the later will be the experimental epoxidation of ethylene with a low coverage of $\mathrm{O}$ adsorbed on an unreconstructed surface. While DFT calculations have shown that the reaction of ethylene with $\mathrm{O}_{\text {ads }}$ can produce EO through an oxometallacycle (OMC) intermediate, ${ }^{17,33}$ the experimental evidence on this mechanism has relied on the production of EO from an OMC formed after EO adsorption on a silver single crystal. ${ }^{77}$ Here we have shown that $\mathrm{O}_{\text {ads }}$ can be prepared and identified in UHV, opening the opportunity to test the complete route of reaction $\mathrm{C}_{2} \mathrm{H}_{4}+\mathrm{O}_{\text {ads }}$ $\rightarrow$ OMC $\rightarrow$ EO predicted by DFT, although the high reactivity of $\mathrm{O}_{\text {ads }}$ towards clean-off reactions will make such studies challenging. 


\section{Conclusions}

We have determined experimentally that on unreconstructed $\mathrm{Ag}(110)$ adsorbed atomic $\mathrm{O}$ has a $\mathrm{BE} \leq 528 \mathrm{eV}$, as earlier predicted by DFT, which is lower than the $p(N \times 1)$ reconstruction and thus, cannot give rise to the $\mathrm{O} 1 \mathrm{~s}$ feature with $\mathrm{BE}$ of 530$531 \mathrm{eV}$ (electrophilic oxygen) believed to be responsible for epoxidation.

Atomic $\mathrm{O}$ adsorbed on the unreconstructed silver surface is present during in situ experiments upon $\mathrm{O}_{2}$ exposure at low $\mathrm{O}$ coverages $(<0.04 \mathrm{ML})$ at $423 \mathrm{~K}$. At higher coverages, the thermodynamically favored O-reconstructions are formed. These findings are supported by DFT. At low temperatures, $c a .120 \mathrm{~K}$, unreconstructed $\mathrm{O}$ can be obtained in UHV and the atomic $\mathrm{O}$ coverage reaches $0.1 \mathrm{ML}$, due to kinetic limitations to form the O-reconstructions, which is a thermally activated process. This species is highly reactive towards clean-off reactions even at 120 $\mathrm{K}$ and reacts rapidly with background gases. These findings suggest that only very low coverage of unreconstructed atomic $\mathrm{O}$ is likely to be present at the silver surface under ethylene epoxidation conditions. Although present at low coverage, the computed barriers to $\mathrm{EO}$ and $\mathrm{AcH}$ indicate that on unpromoted silver EO might be produced as a minority product through reaction with oxygen adsorbed on unreconstructed $\mathrm{Ag}(110)$. Our findings suggest that at least two different species, a covalently bond oxygen-electrophilic oxygen-(with a BE of 530-531 eV) and unreconstructed atomic oxygen (with a $\mathrm{BE} \leq 528 \mathrm{eV}$ ) might participate in the partial oxidation of ethylene. This points to a new way of thinking about one of the most well-studied reactions in chemistry. The fact that not one but multiple oxygen species can participate in epoxidation. This has important implications for the understanding of the mechanism of ethylene epoxidation on silver and of the role of the different oxygen species.

\section{Conflicts of interest}

There are no conflicts to declare.

\section{Acknowledgements}

We thank the Helmholtz-Zentrum Berlin for providing support of the in situ electron spectroscopy activities of the FHI at ISISS beamline in BESSY II and the Max-Planck Gesellschaft for generous founding. We gratefully acknowledge Höchstleistungsrechenzentrum Stuttgart (HLRS) for generous access to the supercomputer HazelHen through the SEES2 project. This project has received funding from the EU-H2020 research and innovation programme under grant agreement No. 654360 having benefitted from the access provided by CNRIOM in ELETTRA Trieste, Italy, within the framework of the NFFA-Europe Transnational Access Activity. T. E. J. acknowledges the Alexander-von-Humboldt foundation for financial support. Open Access funding provided by the Max Planck Society.

\section{References}

1 R. A. van Santen and C. P. M. de Groot, J. Catal., 1986, 98, 530-539.

2 R. A. Van Santen and H. P. C. E. Kuipers, Adv. Catal., 1987, 35, 265-321.

3 J. G. Serafin, A. C. Liu and S. R. Seyedmonir, J. Mol. Catal. A: Chem., 1998, 131, 157-168.

4 V. I. Bukhtiyarov and A. Knop-Gericke, RSC Nanosci. Nanotechnol., 2011, 214-247, DOI: 10.1039/978184755987600214.

5 V. I. Bukhtiyarov, A. I. Nizovskii, H. Bluhm, M. Havecker, E. Kleimenov, A. Knop-Gericke and R. Schlogl, J. Catal., 2006, 238, 260-269.

6 T. C. R. Rocha, A. Oestereich, D. V. Demidov, M. Havecker, S. Zafeiratos, G. Weinberg, V. I. Bukhtiyarov, A. KnopGericke and R. Schlogl, Phys. Chem. Chem. Phys., 2012, 14, 4554-4564.

7 T. C. R. Rocha, M. Havecker, A. Knop-Gericke and R. Schlogl, J. Catal., 2014, 312, 12-16.

8 R. B. Grant and R. M. Lambert, J. Catal., 1985, 93, 92-99.

9 R. B. Grant and R. M. Lambert, Langmuir, 1985, 1, 29-33.

10 T. E. Jones, R. Wyrwich, S. Bocklein, T. C. R. Rocha, E. A. Carbonio, A. Knop-Gericke, R. Schlogl, S. Gunther, J. Wintterlin and S. Piccinin, J. Phys. Chem. C, 2016, 120, 28630-28638.

11 E. A. Carter and W. A. Goddard, J. Catal., 1988, 112, 80-92.

12 E. A. Carter and W. A. Goddard, Surf. Sci., 1989, 209, 243289.

13 V. I. Bukhtiyarov, I. P. Prosvirin and R. I. Kvon, Surf. Sci., 1994, 320, L47-L50.

14 C. T. Campbell and M. T. Paffett, Surf. Sci., 1984, 139, 396416.

15 T. E. Jones, T. C. R. Rocha, A. Knop-Gericke, C. Stampfl, R. Schlogl and S. Piccinin, Phys. Chem. Chem. Phys., 2015, 17, 9288-9312.

16 T. E. Jones, T. C. R. Rocha, A. Knop-Gericke, C. Stampfl, R. Schlogl and S. Piccinin, ACS Catal., 2015, 5, 5846-5850.

17 M. O. Özbek and R. A. van Santen, Catal. Lett., 2013, 143, 131-141.

18 R. W. Joyner and M. W. Roberts, Chem. Phys. Lett., 1979, 60, 459-462.

19 C. T. Au, S. Singhboparai, M. W. Roberts and R. W. Joyner, J. Chem. Soc., Faraday Trans. 1, 1983, 79, 1779-1791.

20 V. I. Bukhtiyarov, A. I. Boronin and V. I. Savchenko, Surf. Sci., 1990, 232, L205-L209.

21 V. I. Bukhtiyarov, M. Hävecker, V. V. Kaichev, A. KnopGericke, R. W. Mayer and R. Schlögl, Catal. Lett., 2001, 74, 121-125.

22 V. I. Bukhtiyarov, Kinet. Catal., 2003, 44, 420-431.

23 V. I. Bukhtiyarov, M. Havecker, V. V. Kaichev, A. KnopGericke, R. W. Mayer and R. Schlogl, Phys. Rev. B: Condens. Matter Mater. Phys., 2003, 67, 235422.

24 S. Bocklein, S. Gunther and J. Wintterlin, Angew. Chem., Int. Ed., 2013, 52, 5518-5521. 
25 S. Gunther, S. Bocklein, J. Wintterlin, M. A. Nino, T. O. Mentes and A. Locatelli, ChemCatChem, 2013, 5, 3342-3350.

26 C. Heine, B. Eren, B. A. J. Lechner and M. Salmeron, Surf. Sci., 2016, 652, 51-57.

27 V. I. Bukhtiyarov, A. I. Boronin, I. P. Prosvirin and V. I. Savchenko, J. Catal., 1994, 150, 268-273.

28 C. T. Campbell and M. T. Paffett, Surf. Sci., 1984, 143, 517535.

29 V. I. Bukhtiyarov, A. I. Boronin and V. I. Savchenko, J. Catal., 1994, 150, 262-267.

30 V. I. Bukhtiyarov, A. I. Boronin, M. P. Oschepkova and V. I. Savchenko, React. Kinet. Catal. Lett., 1989, 39, 21-26.

31 M. O. Ozbek, I. Onal and R. A. van Santen, Top. Catal., 2012, 55, 710-717.

32 M. L. Bocquet and D. Loffreda, J. Am. Chem. Soc., 2005, 127, 17207-17215.

33 S. Linic and M. A. Barteau, J. Catal., 2003, 214, 200-212.

34 L. Savio, A. Gerbi, L. Vattuone, A. Baraldi, G. Comelli and M. Rocca, J. Phys. Chem. B, 2006, 110, 942-947.

35 L. Savio, A. Gerbi, L. Vattuone, R. Pushpa, N. Bonini, S. de Gironcoli and M. Rocca, J. Phys. Chem. C, 2007, 111, 10923-10930.

36 C. I. Carlisle, T. Fujimoto, W. S. Sim and D. A. King, Surf. Sci., 2000, 470, 15-31.

37 L. Vattuone, M. Rocca, C. Boragno and U. Valbusa, J. Chem. Phys., 1994, 101, 713-725.

38 M. E. M. Spruit and A. W. Kleyn, Chem. Phys. Lett., 1989, 159, 342-348.

39 C. T. Campbell, Surf. Sci., 1985, 157, 43-60.

40 H. Albers, W. J. J. Van Der Wal, O. L. J. Gijzeman and G. A. Bootsma, Surf. Sci., 1978, 77, 1-13.

41 H. Albers, W. J. J. Van Der Wal and G. A. Bootsma, Surf. Sci., 1977, 68, 47-56.

42 H. A. Engelhardt and D. Menzel, Surf. Sci., 1976, 57, 591-618.

43 T. Zambelli, J. V. Barth and J. Wintterlin, J. Phys.: Condens. Matter, 2002, 14, 4241-4250.

44 D. E. Starr, Z. Liu, M. Havecker, A. Knop-Gericke and H. Bluhm, Chem. Soc. Rev., 2013, 42, 5833-5857.

45 A. Knop-Gericke, E. Kleimenov, M. Hävecker, R. Blume, D. Teschner, S. Zafeiratos, R. Schlögl, V. I. Bukhtiyarov, V. V. Kaichev, I. P. Prosvirin, A. I. Nizovskii, H. Bluhm, A. Barinov, P. Dudin and M. Kiskinova, Adv. Catal., 2009, 52, 213-272.

46 M. Zangrando, M. Finazzi, G. Paolucci, G. Comelli, B. Diviacco, R. P. Walker, D. Cocco and F. Parmigiani, Rev. Sci. Instrum., 2001, 72, 1313-1319.

47 M. Zangrando, M. Zacchigna, M. Finazzi, D. Cocco, R. Rochow and F. Parmigiani, Rev. Sci. Instrum., 2004, 75, 31-36.

48 P. Giannozzi, S. Baroni, N. Bonini, M. Calandra, R. Car, C. Cavazzoni, D. Ceresoli, G. L. Chiarotti, M. Cococcioni, I. Dabo, A. Dal Corso, S. de Gironcoli, S. Fabris, G. Fratesi, R. Gebauer, U. Gerstmann, C. Gougoussis, A. Kokalj, M. Lazzeri, L. Martin-Samos, N. Marzari, F. Mauri, R. Mazzarello, S. Paolini, A. Pasquarello, L. Paulatto, C. Sbraccia, S. Scandolo, G. Sclauzero, A. P. Seitsonen,
A. Smogunov, P. Umari and R. M. Wentzcovitch, J. Phys.: Condens. Matter, 2009, 21, 395502.

49 J. P. Perdew, K. Burke and M. Ernzerhof, Phys. Rev. Lett., 1997, 78, 1396.

50 A. D. Becke and E. R. Johnson, J. Chem. Phys., 2007, 127, 154108.

51 A. Otero-de-la-Roza and E. R. Johnson, J. Chem. Phys., 2012, 136, 174109.

52 A. Dal Corso, Comput. Mater. Sci., 2014, 95, 337-350.

53 N. Marzari, D. Vanderbilt, A. De Vita and M. C. Payne, Phys. Rev. Lett., 1999, 82, 3296-3299.

54 E. Pehlke and M. Scheffler, Phys. Rev. Lett., 1993, 71, 23382341.

55 W.-X. Li, C. Stampfl and M. Scheffler, Phys. Rev. B: Condens. Matter Mater. Phys., 2003, 68, 165412.

56 T. Zambelli, J. V. Barth and J. Wintterlin, Phys. Rev. B: Condens. Matter Mater. Phys., 1998, 58, 12663-12666.

57 W. W. Pai, N. C. Bartelt, M. R. Peng and J. E. Reuttrobey, Surf. Sci., 1995, 330, L679-L685.

58 K. Morgenstern, E. Lægsgaard and F. Besenbacher, in Collective Diffusion on Surfaces: Correlation Effects and Adatom Interactions: Proceedings of the NATO Advanced Research Workshop on Collective Diffusion on Surfaces: Correlation Effects and Adatom Interactions Prague, Czech Republic 2-6 October 2000, ed. M. C. Tringides and Z. Chvoj, Springer Netherlands, Dordrecht, 2001, pp. 201212, DOI: 10.1007/978-94-010-0816-7_18.

59 J. V. Barth, T. Zambelli, J. Wintterlin, R. Schuster and G. Ertl, Phys. Rev. B: Condens. Matter Mater. Phys., 1997, 55, 1290212905.

60 L. Vattuone, M. Rocca, P. Restelli, M. Pupo, C. Boragno and U. Valbusa, Phys. Rev. B: Condens. Matter Mater. Phys., 1994, 49, 5113-5116.

61 M. Smerieri, L. Savio, L. Vattuone and M. Rocca, J. Phys.: Condens. Matter, 2010, 22, 304015.

62 J. F. Moulder, W. F. Stickle, P. E. Sobol and K. D. Bomben, Handbook of X Ray Photoelectron Spectroscopy: A Reference Book of Standard Spectra for Identification and Interpretation of XPS Data, Perkin-Elmer Corporation, USA, 1995.

63 U. Burghaus and H. Conrad, Surf. Sci., 1997, 370, 17-31.

64 U. Burghaus and H. Conrad, Surf. Sci., 1995, 338, L869L874.

65 L. Zhu, W. Zhang, J. Zhu and D. Cheng, Appl. Catal., A, 2017, 538, 27-36.

66 P. Christopher and S. Linic, J. Am. Chem. Soc., 2008, 130, 11264-11265.

67 W.-X. Li, C. Stampfl and M. Scheffler, Phys. Rev. Lett., 2003, 90, 256102.

68 C. Stegelmann, N. C. Schiødt, C. T. Campbell and P. Stoltze, J. Catal., 2004, 221, 630-649.

69 S. Linic and M. A. Barteau, J. Am. Chem. Soc., 2003, 125, 4034-4035.

70 A. Kokalj, P. Gava, S. de Gironcoli and S. Baroni, J. Catal., 2008, 254, 304-309.

71 N. W. Cant and W. K. Hall, J. Catal., 1978, 52, 81-94.

72 M. A. Barteau, M. Bowker and R. J. Madix, J. Catal., 1981, 67, 118-128. 
73 A. G. Sault and R. J. Madix, Surf. Sci., 1986, 172, 598-614. $\quad 77$ A. Lukaski and M. Barteau, Catal. Lett., 2009, $128,9-17$.

74 D. Torres, F. Illas and R. M. Lambert, J. Catal., 2008, 260, 78 S. Linic and M. A. Barteau, J. Am. Chem. Soc., 2004, 126, 380-383. 8086-8087.

75 J. Greeley and M. Mavrikakis, J. Phys. Chem. C, 2007, 111, 79 V. I. Bukhtiyarov, A. I. Boronin, I. P. Prosvirin and 7992-7999.

V. I. Savchenko, J. Catal., 1994, 150, 268-273.

76 D. Ren, H. Xu, J. Li, J. Li and D. Cheng, Mol. Catal., 2017, 441, 92-99. 